\title{
Surface photochemistry: Photodegradation study of pyrene adsorbed onto microcrystalline cellulose and silica
}

\author{
A. S. Oliveira, ${ }^{1, \dagger}$ L. F. Vieira Ferreira, ${ }^{1}$ J. P. Da Silva, ${ }^{1,2}$ and J. C. Moreira ${ }^{3}$ \\ ${ }^{1}$ Centro de Química-Física Molecular - Complexo Interdisciplinar, Instituto Superior Técnico, \\ 1096 Lisboa Codex, Portugal \\ ${ }^{2}$ FCT, Universidade do Algarve, Campus de Gambelas, 8005-139 Faro, Portugal \\ ${ }^{3}$ Centro de Estudos da Saúde do Trabalhador e Ecologia Humana, ENSP, Fundação Oswaldo Cruz, \\ Rua Leopoldo Bulhões 1480, Rio de Janeiro, RJ, 21041-210, Brazil
}

\begin{abstract}
Ground-state diffuse reflectance, time resolved laser-induced luminescence, diffuse reflectance laser flash-photolysis transient absorption and chromatographic techniques were used to elucidate the photodegradation processes of pyrene adsorbed onto microcrystalline cellulose and silica. Ground-state diffuse reflectance showed that on both substrates low concentrations display absorption of pyrene monomers. At high concentrations spectral changes attributed to aggregate formation were observed. Laser induced fluorescence showed that pyrene onto microcrystalline cellulose mainly presents fluorescence from monomers, while for silica, excimer-like emission was observed from low surface loadings $\left(\geq 0.5 \mu \mathrm{mol} \mathrm{g}^{-1}\right)$. Transient absorption and photodegradation studies were performed at concentrations where mainly monomers exist. On silica, pyrene presents transient absorption from its radical cation. On microcrystalline cellulose both radical cation, radical anion and pyrene triplet-triplet absorption were detected. Irradiation followed by chromatographic analysis showed that pyrene decomposes on both substrates. For pyrene on microcrystalline cellulose 1-hydroxypyrene was the main identified photoproduct since in the absence of oxygen further oxidation of 1-hydroxypyrene was very slow. For pyrene on silica photodegradation was very efficient. Almost no 1-hydroxypyrene was detected since in the presence of oxygen it is quickly oxidized to other photooxidation products. On both substrates, pyrene radical cation is the intermediate leading to photoproducts and oxygen it is not involved in its formation.
\end{abstract}

\section{INTRODUCTION}

The understanding of photochemical and photophysical processes of probes included into opaque heterogeneous solids supports has recently greatly improved as a consequence of the development of diffuse reflectance [1, 2] and time-resolved laser-induced techniques [2] and also of the availability of new solid supports [2]. These techniques are now commonly used to access photochemical and photophysics processes in solid phases and they have been applied by us [3-8] to study several organic compounds adsorbed or included in different solid supports such as microcrystalline cellulose [3, 4], silicas [5], silicalite [6, 7], cyclodextrins $[6,7]$ and calix[n]arenes [8]. Furthermore, they are being applied in our group to study several environmental contaminants $[7,9,10]$ namely PAHs adsorbed on different solid supports.

Polycyclic aromatic hydrocarbons (PAHs) comprehend a group of neutral, non polar chemical substances which result from the incomplete combustion of fossil fuels. Due to their poor solubility in water and high solubility in fats they easily bioaccomulate in living tissues. In the environment PAHs are mainly widespread adsorbed or included in complex

${ }^{\dagger}$ E-mail: ASOliveira@ist.utl.pt matrices. Some PAHs possess mutagenic/carcinogenic activities and therefore are considered prioritary pollutants for environmental monitoring [11].

The need of understanding the fate of PAHs in the environment makes important to elucidate their photochemistry in the adsorbed state [12]. In fact, photolytic half-lives of PAHs may greatly vary from solution to the adsorbed state, as for some of them surface adsorption decreases their susceptibility to photolytic degradation [13]. Also for a given PAH adsorbed on different surfaces enormous variations in its photolytic half-lives can occur [14].

Pyrene is frequently used as a model PAH and details of its aqueous photochemistry have previously been reported [15]. On water pyrene undergoes efficient photooxidation by an electron transfer mechanism from the excited pyrene to oxygen to form pyrene radical cation and superoxide and/or oxygen-derived radicals [15]. The influence of surface adsorption on its photophysics and photochemistry has also been studied for silica and other oxide materials [16-18]. Also in the adsorbed state pyrene radical cation is the intermediate leading to photoproducts [16-18].

Microcrystalline cellulose is a remarkable powdered support that effectively protects adsorbed probes from the oxygen action, provided the probe stays entrapped 
into the polymer chains [2-4]. Silica gel is a porous and granular form of amorphous silica formed by a complex net of microscopic pores from which results a very high specific surface area. Its surface area, witch is essentially the internal area of the pore walls, greatly varies with the pore size (from 20 to $750 \mathrm{~m}^{2} \mathrm{~g}^{-1}$ ). On silica, adsorbed probes experiment restricted mobility on pores where they can be easily reached by oxygen $[2,6]$.

In this paper we report the potentialities of using diffuse reflectance and time resolved laser induced techniques together with chromatographic techniques to elucidate and compare the influence of microcrystalline cellulose and silica substrates on pyrene photodegradation pathways.

\section{EXPERIMENTAL SECTION}

Materials. Pyrene (99\%) and 1-Hydroxypyrene (98\%) were purchased from Aldrich in the highest purity available and were used as received. Ethanol (Merck, uvasol grade), methanol and acetonitrile (Merck, Lichrosolv) were also used as received. Molecular sieves (3

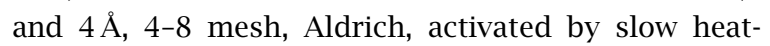
ing up to $250{ }^{\circ} \mathrm{C}$ under vacuum) were used to dry ethanol since very well dried deposition solvent was required for sample preparation. Water was deionized and distilled. Microcrystalline cellulose with $50 \mu \mathrm{m}$ average particle size from Fluka (Microcrystalline cellulose, Fluka DS0) and Silica from Camag (Silica gel for TLC without binder, Camag DS-0, $60 \AA$ pore size) were used without further purification.

Sample preparation. Microcrystalline cellulose was dried prior to use for at least 12 hours in an acrylic chamber with an electrically heated shelf (Heto, Model FD 1.0-110) with temperature control at $40 \pm 1{ }^{\circ} \mathrm{C}$ and at a pressure of ca. $10^{-3}$ Torr. Powdered samples of pyrene on both substrates were prepared by addition of aliquots of a pyrene solution in dry ethanol on previously dried microcrystalline cellulose and unactivated silica followed by slow solvent evaporation from the slurry in a fume cupboard as described in detail by Vieira Ferreira et al. [3a, 6].

Air equilibrated, deoxygenated and oxygen saturated samples were studied. The removal of oxygen was achieved by purging with argon. Oxygen saturation was achieved by the use of a flow of this gas. Samples were kept under gas flow for at least 1 hour.

In order to remove any non-entrapped pyrene from microcrystalline cellulose samples, those were washed with 3 aliquots of $5 \mathrm{ml}$ of dichloromethane, a solvent that does not swell this substrate.

\section{Methods}

Diffuse Reflectance Ground State Absorption Spectra of powdered solid samples of pyrene onto microcrystalline cellulose and silica were registered in the UVVIS regions using an OLIS 14 UV/VIS/NIR spectropho- tometer with a diffuse reflectance attachment from 240 to $450 \mathrm{~nm}$. Further experimental details and description of system calibration used to obtain accurate reflectance (R) measurements are given elsewhere ([2] and references quoted therein).

Laser Induced Fluorescence (LIF) emission measurements of the powdered pyrene samples were performed, at room temperature, in a front-surface arrangement. A diagram of the system is presented in ref. [6]. The system uses the $337.1 \mathrm{~nm}$ pulse (suitable for PAHs excitation) of a $\mathrm{N}_{2}$ laser (Photon Technology Instruments, Model 2000, ca. 600 ps FWHM, $\sim 1.3 \mathrm{~mJ} /$ pulse) as excitation source, coupled to the detection system described in the next paragraph for the DRLFP system [2, 6-8].

Diffuse-Reflectance Laser Flash Photolysis (DRLFP) experiments were carried out in the diffuse reflectance mode, with the second harmonic of a YAG laser (355 nm, ca. $6 \mathrm{~ns}$ FWHM, $\sim 30 \mathrm{~mJ} /$ pulse) from B. M. Industries (Thomson-CSF), model Saga 12-10 [2, 8]. The light arising from the irradiation of solid samples is detected by a gated intensified charge coupled device with nanosecond resolution (ICCD, Oriel model Instaspec V) coupled to a fixed imaging compact spectrograph (Oriel, model FICS 77440). A complete diagram of the system is available from ref. [2]. Transient absorption data are reported as percentage of absorption (\% Abs.), defined as $100 \Delta J_{t} / J_{o}=\left(1-J_{t} / J_{o}\right) 100$, where $J_{o}$ and $J_{t}$ are diffuse reflected light from sample before exposure to the exciting laser pulse and at time $t$ after excitation, respectively [1, 2].

Irradiation, degradation kinetics and product analysis. Photodegradation studies were performed under lamp and laser irradiation conditions. Lamp irradiation studies were conducted in a reactor previously used to study the photochemistry of pesticides [19], chlorophenols [7] and several ketones [8c, 8d, 8e]. The samples were irradiated at $254 \mathrm{~nm}$ using a $16 \mathrm{~W}$ lowpressure mercury lamp (Applied Photophysics) without filters and refrigeration. The samples were placed on Petri dishes and irradiated at a distance of $5 \mathrm{~cm}$ from the lamp housing. Laser irradiation $(355 \mathrm{~nm})$ was performed using the system described above. The solid powdered samples were placed in $0.5 \mathrm{~cm}$ quartz cells and were mixed every 10 minutes of irradiation time.

The photodegradation products were extracted by washing the irradiated samples with methanol. Photolysis was followed by HPLC using a Merck-Hitachi 655A11 chromatograph equipped with detectors 655A-22 UV. A column LiChroCART 125 (RP-18, $5 \mu \mathrm{m}$ ) Merck was used and the runs were performed using mixtures water/acetonitrile as the eluent. The extracts were also analysed by GC-MS using a Hewlett Packard 5890 Series II gas chromatograph with a 5971 series mass selective detector (E.I. 70 eV). An Optima-5-MS capillary column with $30 \mathrm{~m}$ length and $0.25 \mathrm{~mm}$ I.D. (Macherey-Nagel) was used. The initial temperature $70^{\circ} \mathrm{C}$ was maintained 
during 5 min and then a rate of $5{ }^{\circ} \mathrm{C} / \mathrm{min}$ was used until a final temperature of $250{ }^{\circ} \mathrm{C}$ is reached. Analyses were conducted on irradiated and control samples, kept in the dark during irradiation. Controls showed no sign of pyrene degradation.

\section{RESULTS AND DISCUSSION}

3.1. Ground state diffuse reflectance absorption spectra. Figure 1 shows the typical remission functions for low and high concentrations of pyrene adsorbed from ethanol onto microcrystalline cellulose (Figure 1a) and silica (Figure $1 \mathrm{~b}$ ) from $250 \mathrm{~nm}$ to $400 \mathrm{~nm}$. Pyrene on microcrystalline cellulose, for concentrations up to $1 \mu \mathrm{mol} \mathrm{g}^{-1}$ (curve 1 , Figure $1 \mathrm{a}$ ), presents the absorption of monomers, i.e., the $\mathrm{S} 0 \rightarrow \mathrm{S} 2$ from $300 \mathrm{~nm}$ to $370 \mathrm{~nm}$, with the maximum located at $340 \mathrm{~nm}$ and vibrational shoulders at $324 \mathrm{~nm}$ and $310 \mathrm{~nm}$; the $\mathrm{S} 0 \rightarrow \mathrm{S} 3$ absorption is also observed from $250 \mathrm{~nm}$ to $290 \mathrm{~nm}$ with maxima at $280 \mathrm{~nm}$ and $270 \mathrm{~nm}$ respectively [12, $15,20]$. The increase of pyrene concentration for loading up to $25 \mu \mathrm{mol} \mathrm{g}^{-1}$ (curve 2, Figure 1a) produces a net increase in the absorption intensity of the first vibrational shoulder of the $\mathrm{S} 0 \rightarrow \mathrm{S} 2$ transition together with an overall broadening and lost of vibrational resolution of the spectra and a 2-5 nm bathochromic shift on the maxima of the $\mathrm{S} 0 \rightarrow \mathrm{S} 2$ absorption band. Similar spectral changes with the increase of the concentration were observed by us for other probes and attributed to ground state aggregate formation [3, 4]. For the highest concentrations it is also possible to distinguish, at $378 \mathrm{~nm}$, the weak $\mathrm{S} 0 \rightarrow \mathrm{S} 1$ transition band of pyrene.

Silica samples with concentrations up to $1 \mu \mathrm{mol} \mathrm{g}^{-1}$ (curve 1, Figure $1 \mathrm{~b}$ ) show the $\mathrm{S} 0 \rightarrow \mathrm{S} 2$ absorption peaking at $330 \mathrm{~nm}$ with shoulders at $315 \mathrm{~nm}$ and $302 \mathrm{~nm}$ and the $\mathrm{S} 0 \rightarrow \mathrm{S} 3$ one at $270 \mathrm{~nm}$ and $258 \mathrm{~nm}$. The increase of the concentration from 1 to $25 \mu \mathrm{molg}^{-1}$ produced practically no changes on the spectra up to $340 \mathrm{~nm}$ (curve 2, Figure 1b). Shape, resolution and relative intensity of the $\mathrm{S} 0 \rightarrow \mathrm{S} 3$ and $\mathrm{S} 0 \rightarrow \mathrm{S} 2$ absorption bands were kept irrespective the concentration increase. However, for wavelengths higher than $340 \mathrm{~nm}$, it is clear the growth of a broad band that extends up to $400 \mathrm{~nm}$. In this region and for concentrations higher than $1 \mu \mathrm{molg}^{-1}$ it is still possible to distinguish the $\mathrm{S} 0 \rightarrow \mathrm{S} 1$ band approximately at the some position observed to microcrystalline cellulose. The appearance of similar read-shifted bands is well known for several PAHs adsorbed on silica at surface coverages well below monolayer and was attributed to another ground state pair/aggregate formation [12, 16a, 17a, 17b] which absorbs predominantly at lower energies.

3.2. Time resolved laser induced fluorescence. Figure 2 presents the time-resolved fluorescence of low and high concentrations of pyrene on microcrystalline cellulose. The use of a gated intensified charged cou-
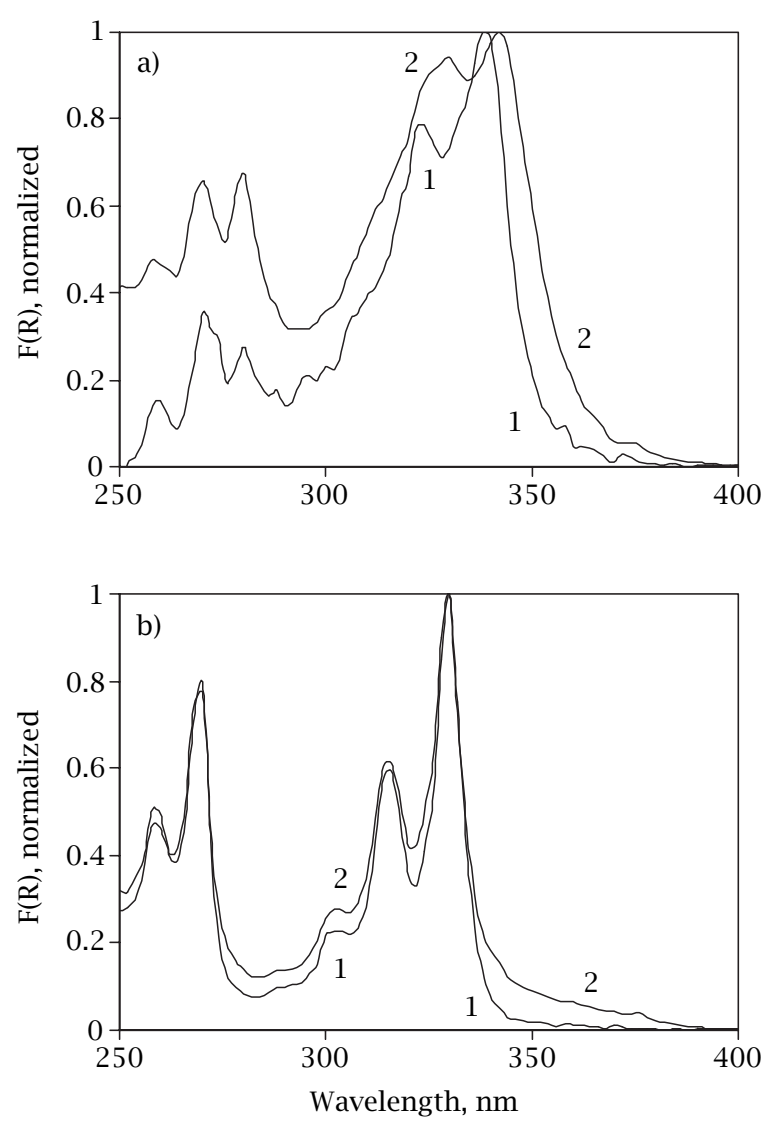

Figure 1. Remission function for a) Pyrene onto microcrystalline cellulose and b) Pyrene on silica normalized at unit at the maximum of the monomer. Concentrations are $1 \mu \mathrm{molg}^{-1}$ (curve 1) and $25 \mu \mathrm{mol} \mathrm{g}^{-1}$ (curve 2).

pled device detector with a 2 ns time gate enabled us to obtain time-resolved emission spectra with nanosecond resolution [2, 6-9]. Figure $2 \mathrm{a}$ shows the fluorescence of a $0.5 \mu \mathrm{molg}^{-1}$ pyrene sample on microcrystalline cellulose. At this concentration pyrene displays a strong structured emission, peaking at $395 \mathrm{~nm}$. Identical behaviour is observed for all concentrations up to $1 \mu \mathrm{mol} \mathrm{g}-1$. This emission can easily be identified as the typical emission from pyrene monomers and its presence indicates that monomers are the predominant species on this support for this range of concentrations [17a]. For higher loadings $\left(\geq 25 \mu \mathrm{mol} \mathrm{g}^{-1}\right)$ of the probe (Figure $2 b$ ) we observe the appearance of a small broad emission band, that coexists with that of the monomer at higher wavelengths $(\sim 470 \mathrm{~nm})$ and has a much shorter lifetime than the latter (ca. $15 \mathrm{~ns}$ ). This emission is well-known for pyrene and arises from its excimer [17].

Figure 3 shows that for pyrene deposited on silica a much different behaviour is observed. In this case, fluorescence arising exclusively from pyrene monomers could only be detected for much diluted samples 

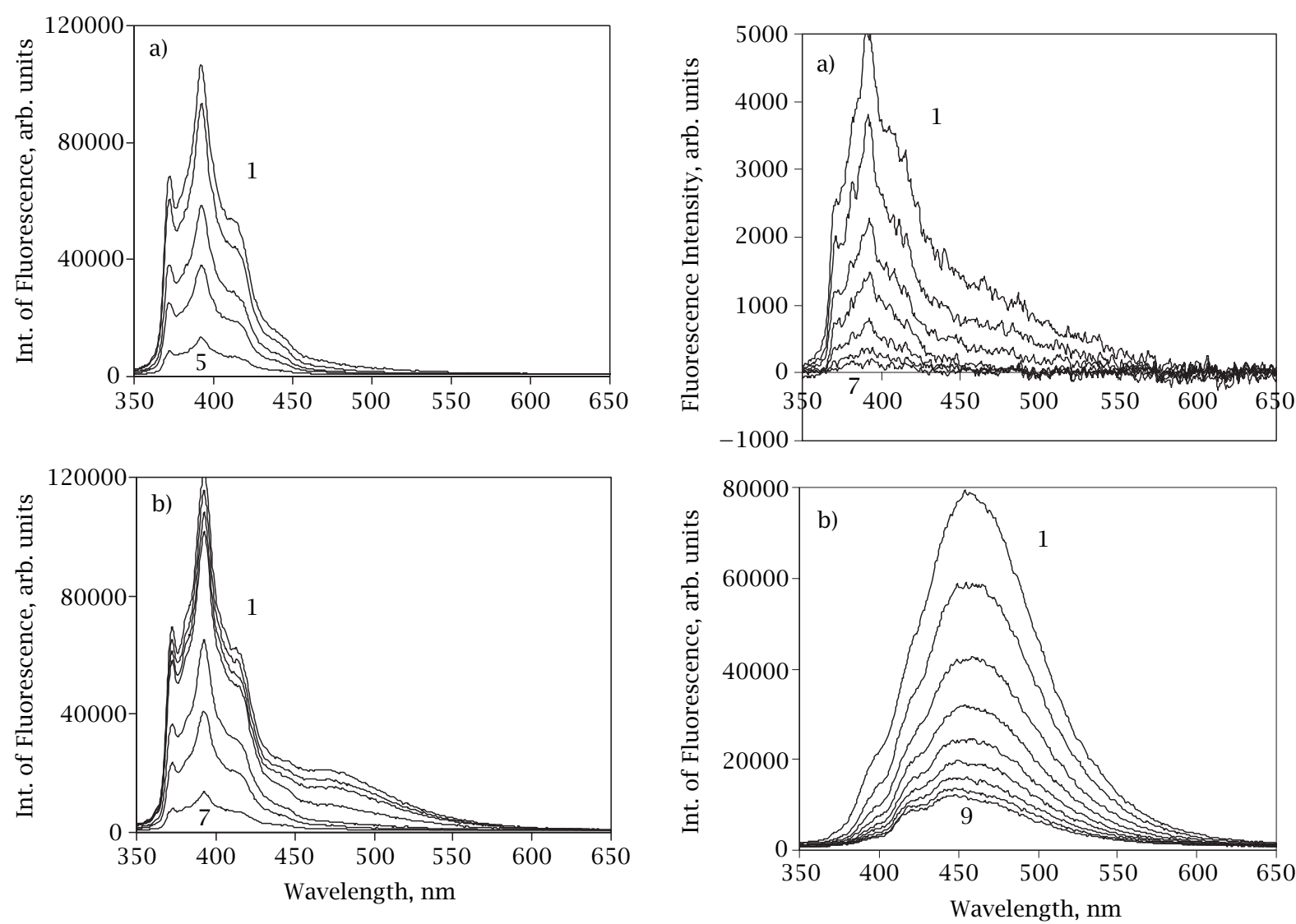

Figure 2. Room-temperature laser induced fluorescence spectra of Pyrene onto microcrystalline cellulose for a) $0.5 \mu \mathrm{mol} \mathrm{g}^{-1}$; curves $1,2,3,4$, and 5 were recorded 0 , 50, 150, 250, and $500 \mathrm{~ns}$ after laser pulse. b) $25 \mu \mathrm{mol} \mathrm{g}^{-1}$; curves $1,2,3,4,5,6$, and 7 were recorded $0,5,10,50$, 150,250 , and $500 \mathrm{~ns}$ after laser pulse. The excitation wavelength was $337 \mathrm{~nm}$.

$\left(0.1 \mu \mathrm{molg}^{-1}\right.$, Figure 3a). For concentrations as low as $0.5 \mu \mathrm{molg}^{-1}$, monomer (peaking at $392 \mathrm{~nm}$ ) and excimer-like (at $472 \mathrm{~nm}$ ) emissions already coexists (data not shown); but monomer emission still predominates; however at higher concentrations pyrene on silica exhibit almost exclusively excimer-like emission as can be seen in Figure $5 \mathrm{~b}$ for a $25 \mu \mathrm{molg}^{-1}$ sample. This excimer-like emission is ascribed to the strong non structured band that appears at wavelength higher than the monomer $(\sim 470 \mathrm{~nm})$.

Comparing the fluorescence results for both substrates, we can say that on microcrystalline cellulose, although some excimer emission is detected for the highest concentrated samples, we can consider that the emission of pyrene is chiefly originated from its monomers. On the contrary, pyrene emission on silica is dominated by excimer-like emission, i.e., that originated by their ground state pairs [17]. Very strong excimer like emission occurs for all silica samples where it

Figure 3. Room-temperature laser induced fluorescence spectra of Pyrene on silica for a concentration of a) $0.1 \mu \mathrm{mol} \mathrm{g}^{-1}$; curves $1,2,3,4,5,6$, and 7 were recorded $5,20,60,100,200,300$, and $400 \mathrm{~ns}$ after laser pulse. b) $25 \mu \mathrm{mol} \mathrm{g}{ }^{-1}$; curves $1,2,3,4,5,6,7,8$, and 9 were recorded $0,10,20,30,40,50,60,70$, and $80 \mathrm{~ns}$ after laser pulse. The excitation wavelength was $337 \mathrm{~nm}$.

is easy to identify the presence of the red-shift ground state absorption band attributed to ground state aggregate formation. Much weaker excimer like emission coexists with that from the monomers starting from very low concentrations $\left(\geq 0.5 \mu \mathrm{mol} \mathrm{g}^{-1}\right)$, where the presence of ground state aggregates, although not so evident, can not be ruled out.

\subsection{Diffuse reflectance laser flash photolysis.}

Time-resolved transient absorption spectra of pyrene on microcrystalline cellulose and silica samples were obtained by diffuse reflectance laser flash photolysis, technique developed in the 80's by Wilkinson and coworkers [1, 2]. All spectra were obtained exciting with the $355 \mathrm{~nm}$ pulse of a Nd:Yag laser with an average energy of $30 \mathrm{~mJ} /$ pulse.

The main goal of this study is to elucidate the photodegradation pathways of pyrene on the two above mentioned solid supports. Aggregated species 

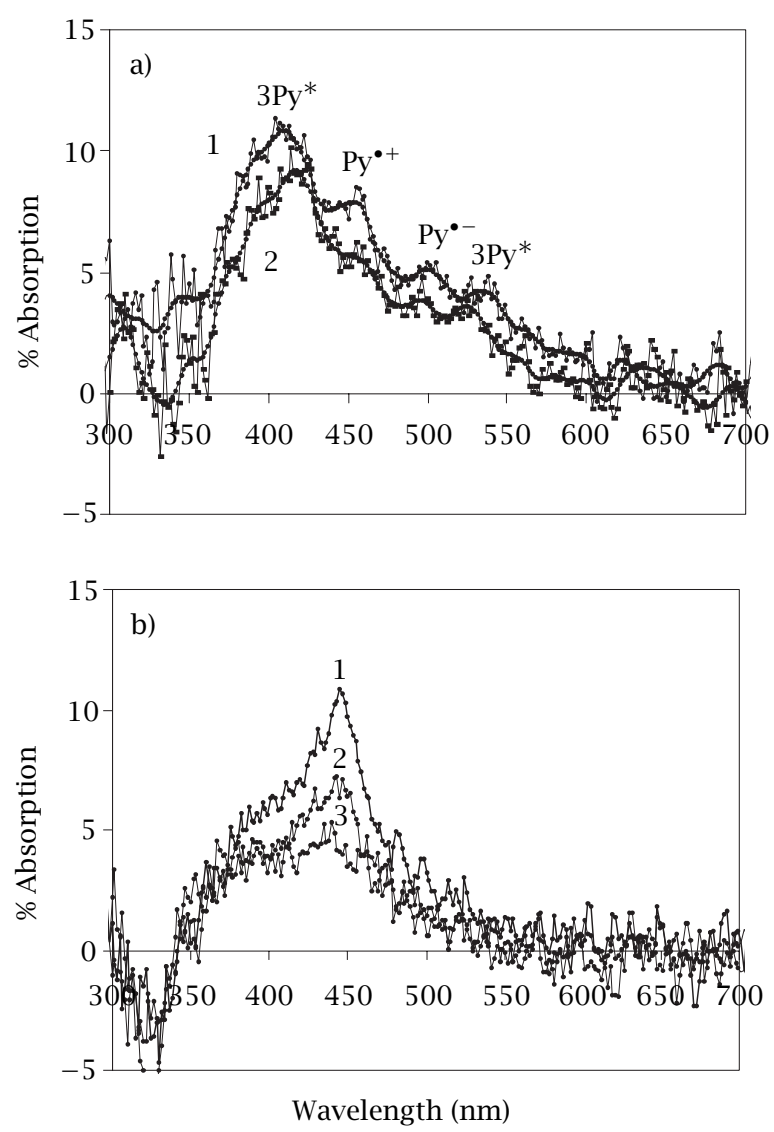

Figure 4. Time-resolved absorption spectra of a) Pyrene onto microcrystalline cellulose for an air equilibrated $10 \mu \mathrm{mol} \mathrm{g}^{-1}$ sample. Curves 1 and 2 were recorded respectively $20 \mu \mathrm{s}$ and $1 \mathrm{~ms}$ after laser pulse. b) Pyrene on silica for an argon purged $0.1 \mu \mathrm{mol} \mathrm{g}^{-1}$ sample. Curves 1,2 , and 3 were recorded respectively $5 \mu \mathrm{s}, 100 \mu \mathrm{s}$, and $20 \mathrm{~ms}$ after laser pulse.

are know as being able to act as light sinks without inducing any photochemistry and in this way, they can effectively inhibit PAH photodegradation [17a]. For both substrates, photodegradation studies were carried out at concentrations where mainly monomers exist (see Section 3.4). Furthermore, low concentrations are the most relevant from the environmental point of view since pollutants mostly exist in these systems in trace amounts. Accordingly, we probed pyrene transient absorption in the adsorbed state at concentrations where monomers are the predominant species.

Figure $4 \mathrm{a}$ presents the transient absorption spectra for an air-equilibrated $10 \mu \mathrm{mol} \mathrm{g}^{-1}$ sample on microcrystalline cellulose. The spectrum shows four absorption peaks respectively at $415 \mathrm{~nm}, 450-455 \mathrm{~nm}$, $490 \mathrm{~nm}$ and $520-530 \mathrm{~nm}$. According to the reported in the literature, for pyrene in solution [21] and other surfaces [16, 18], the absorption bands at $415 \mathrm{~nm}$ and 520$530 \mathrm{~nm}$ are those from de triplet-triplet absorption of pyrene [16b, 16c], the $450-455 \mathrm{~nm}$ band arises from the absorption of the pyrene cation radical [16b, 16c] and the $490 \mathrm{~nm}$ band is originated by the absorption of the pyrene anion radical [16b,16c]. Triplet state of pyrene is very efficiently quenched by oxygen in homogeneous solutions [21]. In microcrystalline cellulose, because oxygen can not penetrate between the polymer chains, pyrene triplet state can easily be seen for air equilibrated samples. In fact, this result is a clear prove of the protective effect from oxygen quenching provided by the inclusion onto microcrystalline cellulose. Within experimental error, we obtained the same result for argon purged, air equilibrated or oxygen saturated non-washed and washed samples (results not shown). This shows that triplets are well entrapped between the cellulosic chains and are not easily reached by oxygen, even when the sample is purged with it. This result it is also a good measure of how adequate is our sample preparation method for cellulose samples: the fact that non-washed and washed samples present the same transient absorption shows that in the non-washed sample there are no significant amount of pyrene outside de polymer chains which can be reached by oxygen, therefore quenching its triplet excited state.

For a lower concentration of pyrene on microcrystalline cellulose $\left(0.5 \mu \mathrm{mol} \mathrm{g}^{-1}\right)$ the obtained results were identical (results not shown). This is in agreement with the above observed from ground state absorption and time resolved luminescence, i.e., the photophysics of pyrene on cellulose for the concentration range under study (up to $25 \mu \mathrm{mol} \mathrm{g}{ }^{-1}$ ) is essentially the same as it arises from the monomers that are the only species present in the all range of concentration.

Figure $4 \mathrm{~b}$ shows the time-resolved transient absorption spectra of argon purged $0.5 \mu \mathrm{mol} \mathrm{g}^{-1}$ pyrene on silica sample. Apart the higher percentage of absorption obtained, this transient absorption spectrum is identical to the one measured for a $0.1 \mu \mathrm{molg}^{-1}$ sample (results not shown). The later is a sufficiently low concentration for ground state pairs/aggregates not to be present (not detected in ground state absorption neither on fluorescence). The transient absorption spectrum is dominated by a sharp absorption at $445 \mathrm{~nm}$ that is still there $20 \mathrm{~ms}$ after de laser pulse. This transient is a clear evidence for the formation of the radical cation of pyrene on silica, and its formation is well documented by several authors [16b, 16c]. As seen above the absorption spectra of the pyrene cation radical peaks at about $445 \mathrm{~nm}$ and lives in the millisecond time scale.

Accordingly to what was reported before for silica, pyrene can easily be reached by oxygen that efficiently quenches its triplet [16c]; on the other hand oxygen does not quenches radical cation and so on this surface only pyrene radical cation is usually seen [16c]. So on silica, pyrene radical cation is the only detected transient. Nevertheless, we found that oxygen saturation of the silica samples produced, within experimental error, 

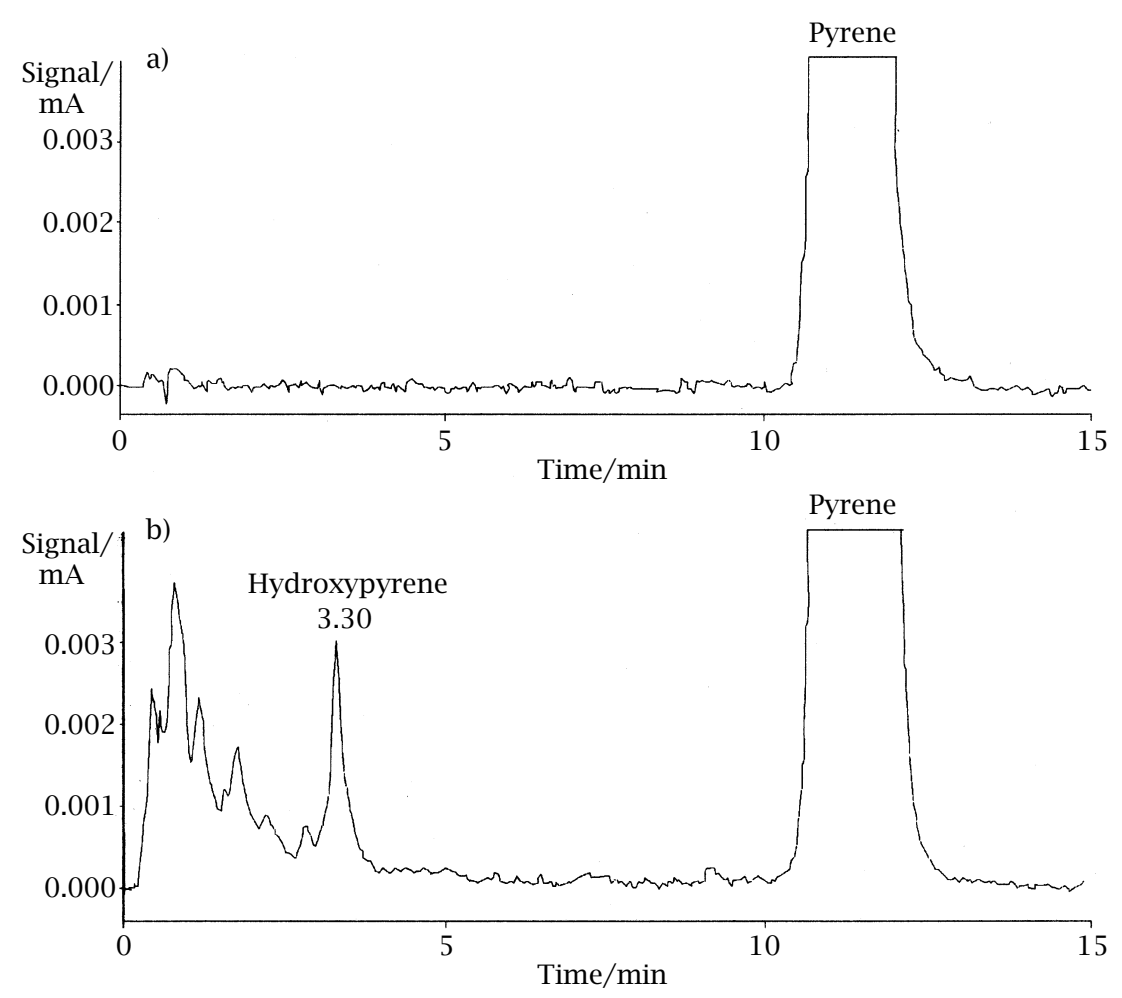

Figure 5. Typical chromatogram (HPLC, diode array detector, $\lambda_{\text {analysis }}=350 \mathrm{~nm}$ ) of the extract of a a) non-irradiated and b) irradiated $(254 \mathrm{~nm})$, sample of pyrene on microcrystalline cellulose.

no increase in the amount of radical cation (result not shown) but argon purged silica samples showed a net increase in the absorption of the radical cation, comparatively to the air equilibrated samples (result not shown).

Argon purged samples (Figure 4b) present an overall spectral reinforcement and although the increase of pyrene triplet could not be ruled out at smaller and higher wavelengths than those of the radical cation, it is this later one that experiments the most striking increase, displaying a $445 \mathrm{~nm}$ strong sharp absorption. This result indicates that the role of oxygen on radical cation formation is a minor one on this support. This result is also supported by the transient absorption spectra obtained on cellulose were molecular oxygen is not present and radical cation is still observed.

3.4. Photodegradation studies. The photodegradation studies were performed on samples where only the pyrene monomer is present to rule out the effects of aggregate formation. The degradation kinetics studies under lamp irradiation conditions $(254 \mathrm{~nm})$ indicated that pyrene undergoes photodegradation on both supports. One-hour irradiation converts $40 \%$ of the initial pyrene on cellulose while on silica a $70 \%$ conversion was found (samples containing $10 \mu \mathrm{mol} \mathrm{g}^{-1}$ ). This result is in agreement with the time resolved luminescence and transient absorption studies, which suggested that the photochemistry of pyrene is strongly dependent on the solid support. Figure 5 presents an HPLC chromatogram of the extract of an irradiated sample of pyrene $(254 \mathrm{~nm})$ on microcrystalline cellulose. The results clearly indicate that 1-hydroxypyrene is one of the major degradation products on this solid support. The assignment was based on analysis of an authentic sample. On silica 1-hydroxypyrene was also detected but in lower concentrations. In both supports, the results also indicated the formation of other degradation products having lower retention time than that of 1-hydroxypyrene, being therefore more polar. These results clearly indicate that photodegradation can play an important role in the decontamination of pyrene at the solid/gas interface in environmental systems, since it can leads to the formation of less persistent polar compounds. Figure 6 presents chromatograms of extracts of laser-irradiated samples $(355 \mathrm{~nm}, 30 \mathrm{~mJ} /$ pulse) on both supports. In these irradiation conditions 1-hydroxypyrene is also one of the major degradation products on microcrystalline cellulose and only trace amounts of it were detected on silica. However in these irradiation conditions the photoproducts are higher in number, indicating that 


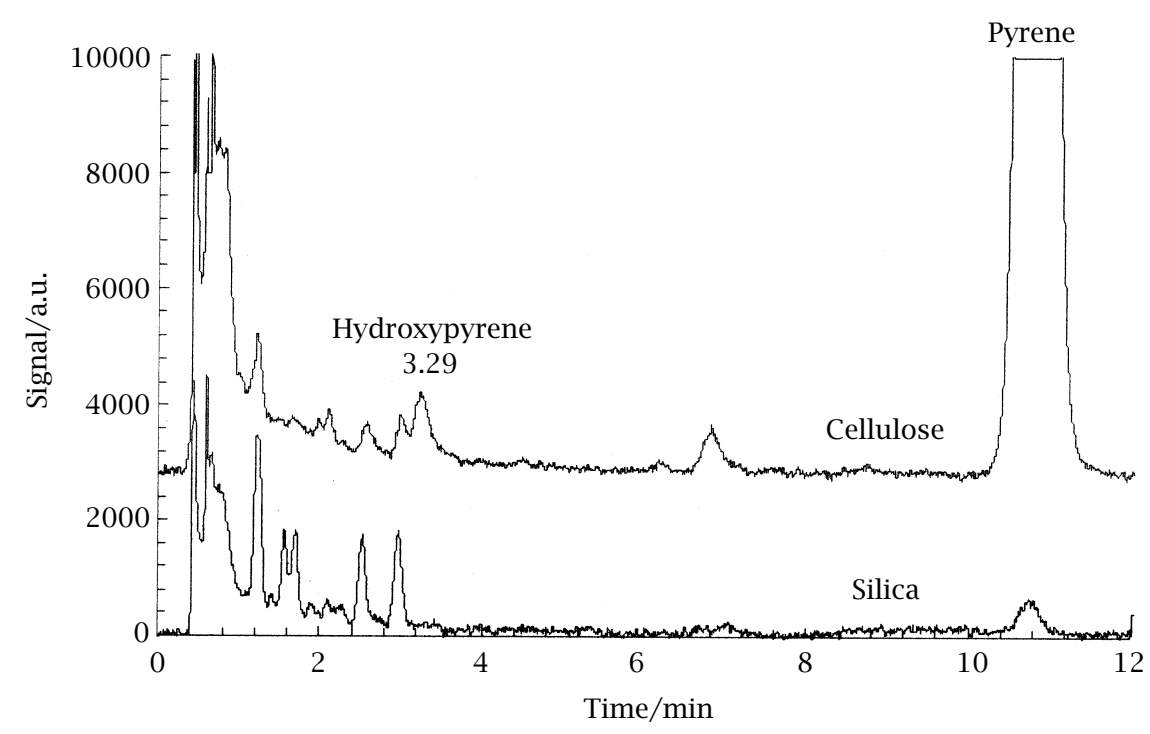

Figure 6. Chromatograms (HPLC, UV-Vis detector, $\left(\lambda_{\text {analysis }}=350 \mathrm{~nm}\right)$ of the extract of laser irradiated $(355 \mathrm{~nm}$, $30 \mathrm{~mJ} /$ pulse) samples of pyrene on microcrystalline cellulose $\left(10 \mu \mathrm{mol} \mathrm{g}^{-1}\right)$ and silica $\left(0.5 \mu \mathrm{mol} \mathrm{g}^{-1}\right)$.

other degradation pathways are available. This result can be attributed to the occurrence of biphotonic processes associated to laser irradiation of powdered samples [8e].

\subsection{Mechanism of pyrene photodegradation on microcrystalline cellulose and silica surfaces. On} silica, pyrene radical cation is the only detected transient. According to literature, radical cation can be formed either by direct photoionization or by electron transfer from the excited pyrene to molecular oxygen [17a]. Nevertheless, we found that oxygen saturation of the silica samples produced, within experimental error, no increase in the amount of radical cation (result not shown) but argon purged silica samples showed a net increase in the absorption of the radical cation, comparatively to the air equilibrated samples. This result suggest that, although molecular oxygen has been suggested to promote the radical cation formation in pyrene on surfaces [17a] and of several other probes in zeolites [22] its role on the radical cation formation on silica it is clearly a minor one. This result is in further agreement with the transient absorption spectra obtained on microcrystalline cellulose. In fact, despite of the protection of this support to molecular oxygen, the radical cation is still one of the main transients. On both substrates a different mechanism should be involved since the radical cation can be formed, either by monophotonic or biphotonic processes, without the presence of oxygen. On silica, although we used an unactivated silica, some Lewis acid sites should be present and they are probably the ones that receive the electron lost during radical cation formation. The increase in the radical cation absorption observed in argon purged samples suggests that another pathway that leads to this species involves also the triplet state that is not quenched in these conditions.

On microcrystalline cellulose, pyrene radical cation can also be produced by a different mechanism that does not involve oxygen as shown by the transient absorption experiments on this support. Effectively, although the entrapment within microcrystalline cellulose clearly protects the included probes from being reached by oxygen (as unequivocally proves the detection of pyrene triplet state on this substrate) pyrene radical cation is also present in this support together with pyrene radical anion. The simultaneous detection of this three species is the key for the elucidation of pyrene photodegradation mechanism on microcrystalline cellulose. In fact in the absence of oxygen, pyrene radical cation is still formed and determines the simultaneous formation of the radical anion. This latter species can be form by trapping the ejected electron (see cellulose route part I on Scheme 1).

On silica and in the presence of water, pyrene radical cation easily leads to the formation of 1hidroxypyrene. This latter, in the presence of oxygen, is further oxidized to more polar oxidation products. All these results (see silica route on part II of Scheme 1) are in agreement with previous reports for pyrene on silica [17a].

On microcrystalline cellulose, 1-hidroxypyrene is the main identified photoproduct. As in silica, the formation of the pyrene radical cation on microcrystalline 
<smiles></smiles><smiles></smiles>

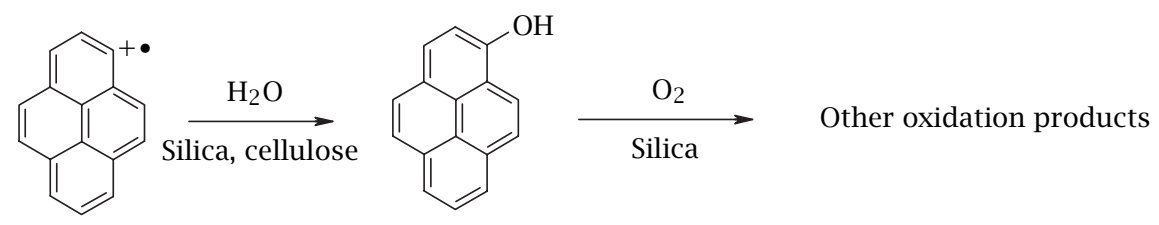

Scheme 1.

cellulose easily accounts for 1-hidroxypyrene formation (see cellulose route on part II of Scheme 1). For 1-hidroxypyrene included molecules further oxidation was very slow since the amount of available oxygen is very limited. Furthermore, although all the other smaller more oxidized photoproducts could be detected on both substrates they were always unequivocally much more significant on silica.

The role of molecular oxygen on the degradation of 1-hidroxypyrene was further confirmed by the comparison of the photoproduct distribution on silica and cellulose under laser irradiation conditions. In fact, while on cellulose 1-hidroxypyrene is still one of the major degradation products, in silica it was only detected in traces amounts (see Figure 6). Based on these results we proposed the summarized mechanism of pyrene photodegradation on microcrystalline cellulose and silica surfaces shown on Scheme 1.

\section{CONCLUSION}

Ground-state diffuse reflectance, time resolved laserinduced luminescence, diffuse reflectance laser flashphotolysis transient absorption and chromatographic techniques used in this study proved to be complementary techniques for the study of the photodegradation processes of pyrene adsorbed on microcrystalline cellulose and silica. These allowed us to establish a more clear picture of the degradation pathways of pyrene on both substrates. We have shown that pyrene radical cation is the key intermediate specie leading to photoproducts on both substrates and also that oxygen is not involved in its formation. 1-Hydroxypyrene was the main identified photoproduct for pyrene on microcrystalline cellulose, since further oxidation of the entrapped photoproduct was very inefficient. For pyrene on silica, photodegradation was much more efficient. Therefore 1-hydroxypyrene in the presence of oxygen it is rapidly further oxidized.

\section{ACKNOWLEDGMENTS}

Equipment was financed by project Praxis/P/Qui/ 10023/98. L.F.V.F. and J.C.M. thank ICCTI \CAPES for financial support. A.S.O. (BPD SFRH/BPD/3650/2000) and J.P.S. (BPD SFRH/BPD/15589/2001) gratefully acknowledge Fundação para a Ciência e Tecnologia for theirs Post-Doctoral fellowships. 


\section{REFERENCES}

[1] (a) R. W. Kessler and F. Wilkinson, J. Chem. Soc. Faraday Trans. I 77 (1981), 309; (b) F. Wilkinson and G. P. Kelly, in Photochemistry on Solid Surfaces, (M. Anpo and T. Matsuara, Eds.), Elsevier, Amsterdam, 1989, p. 31.

[2] (a) L. F. Vieira Ferreira, Química 72 (1999), 28; (b) A. M. Botelho do Rego and L. F. Vieira Ferreira, in Handbook of Surfaces and Interfaces of Materials, Vol. 2, (H. S. Nalwa, Ed.), Academic Press, 2001, Chap. 7, p. 275.

[3] (a) L. F. Vieira Ferreira, J. C. Netto-Ferreira, I. V. Khmelinskii, A. R. Garcia, and S. M. B. Costa, Langmuir 11 (1995), 231; (b) L. F. Vieira Ferreira, A. R. Garcia, M. R. Freixo, and S. M. B. Costa, J. Chem. Soc. Faraday Trans. 89 (1993), 1937; (c) L. F. Vieira Ferreira, M. R. Freixo, A. R. Garcia, and F. Wilkinson, J. Chem Soc. Faraday Trans. 88 (1992), 15.

[4] (a) L. F. Vieira Ferreira, A. S. Oliveira, F. Wilkinson, D. R. Worrall, J. Chem. Soc. Faraday Trans. 92 (1996), 1217; (b) A. S. Oliveira, L. F. Vieira Ferreira, D. R. Worrall, and F. Wilkinson, J. Chem. Soc. Faraday Trans. 92 (1996), 4809; (c) A. M. Botelho do Rego, L. M. Penedo Pereira, M. J. Reis, A. S. Oliveira, and L. F. Vieira Ferreira, Langmuir 13 (1997), 6787; (d) A. S. Oliveira, P. Almeida, and L. F. Vieira Ferreira, Coll. Czech Chem. Comm. 64 (1999), 459.

[5] L. F. Vieira Ferreira, M. J. Lemos, M. J. Reis, and A. M. Botelho do Rego, Langmuir 16 (2000), 5673.

[6] L. F. Vieira Ferreira, A. S. Oliveira, and J. C. NettoFerreira, in Fluorescence Microscopy and Fluorescent Probes 3, (A. Kotyc, Ed.), Espero Publishing, Prague, 1999, p. 199.

[7] (a) J. P. Da Silva, L. F. Vieira Ferreira, A. M. Da Silva, and A. S. Oliveira, J. Photochem. and Photobiol. A: Chem. 151 (2002), 157; (b) J. P. Da Silva, L. F. Vieira Ferreira, A. M. Da Silva, and A. S. Oliveira, Env. Sci. Technol. 37 (2003), 4798.

[8] (a) L. F. Vieira Ferreira, M. R. Vieira Ferreira, A. S. Oliveira, T. J. F. Branco, J. V. Prata, and J. C. Moreira, Physical Chemistry Chemical Physics. 4 (2002), 204; (b) L. F. Vieira Ferreira, M. R. Vieira Ferreira, A. S. Oliveira, and J. C. Moreira, Journal of Photochemistry and Photobiology 153 (2002), 11; (c) L. F. Vieira Ferreira, I. Ferreira Machado, A. S. Oliveira, M. R. Vieira Ferreira, J. P. Da Silva, and J. C. Moreira, J. Phys. Chem. B 106 (2002), 12584; (d) L. F. Vieira Ferreira, M. R. Vieira Ferreira, J. P. Da Silva, I. Ferreira Machado, A. S. Oliveira, and J. V. Prata, Photochem. Photobiol. Sci. 2 (2003), 1002.
[9] A. S. Oliveira, M. B. Fernandes, J. C. Moreira, and L. F. Vieira Ferreira, J. Bras. Chem. Soc. 13 (2002), 245.

[10] M. M. Higarashi, J. C. Moreira, A. S. Oliveira, and L. F. Vieira Ferreira, Química 79 (2000), 16.

[11] Report No. EPA-440/4-79-029.

[12] R. Dabestany, I. N. Ivanov, Photochem. Photobiol. 70 (1999), 10.

[13] (a) W. A. Korfmacher, E. Wehry, G. Mamantov, and D. F. S. Natusch, Environ. Sci. Technol. 14 (1980), 1094; (b) W. A. Korfmacher, D. F. S. Natusch, D. R. Taylor, G. Mamantov, and E. Wehry, Science 207 (1980), 763.

[14] (a) T. D. Behymer and R. A. Hites, Environ. Sci. Technol. 19 (1985), 1004; (b) T. D. Behymer and R. A. Hites, Environ. Sci. Technol. 22 (1988), 1311.

[15] M. E. Sigman, P. F. Schuler, M. M. Ghosh, and R. Dabestany, Environ. Sci. Technol. 32 (1998), 3980.

[16] (a) R. Krasnansky, J. K. Thomas, J. Photochem. Photobiol. A: Chem. 57 (1991) 81; (b) X. Liu, K. K. Iu, and J. K. Thomas, Langmuir 8 (1992), 539; (c) S. Pankasem, and J. K. Thomas, Phys. Chem. 95 (1991), 6990; (d) S. Pankasem, and J. K. Thomas, Phys. Chem. 95 (1991), 7385; (e) G. Beck and J. K. Thomas, Chem. Phys. Lett. 94 (1983), 563.

[17] (a) C. A. Reyes, M. Medina, C. Crespo-Hernandez, M. Z. Cedeno, R. Arce, O. Rosario, D. M. Steffenson, I. N. Ivanov, M. E. Sigman, and R. Dabestany, Environ. Sci. Technol. 34 (2000), 415; (b) R. Dabestany, InterAm. Photochem. Soc. News 20 (1997), 24.

[18] (a) K. Hara, P. de Mayo, W. R. Ware, C. Weedon, G. S. K. Wong, and K. C. Wu, Chem. Phys. Lett. 69 (1980), 105; (b) R. Bauer, P. de Mayo, W. R. Ware, and K. C. Wu, J. Phys. Chem. 86 (1982), 3781.

[19] (a) J. P. Da Silva, A. M. Da Silva, and I. V. Khmelinskii, Chemosphere 45 (2001), 875; (b) J. P. Da Silva, A. M. Da Silva, I. V. Khmelinskii, J. M. G. Martinho, and L. F. Vieira Ferreira, J. Photochem. Photobiol. A: Chem. 142 (2001), 31; (c) J. P. Da Silva, L. F. Vieira Ferreira, and A. M. Da Silva, J. Photochem. Photobiol. A: Chem. 154 (2003), 293.

[20] (a) UV Atlas of Organic Compounds, Vol III, Butherworths, Verlag Chemie, London, 1967; (b) S. L. Murov, I. Carmichael, and G. L. Hug, Handbook of Photochemistry, 2nd Ed. Rev. and expanded, 1993.

[21] J. K. Thomas, J. T. Richards, and G. West, J. Phys. Chem 74 (1970), 4137.

[22] G. Hermenegildo and D. H. Roth, Chem. Rev. 102 (2002), 3947. 


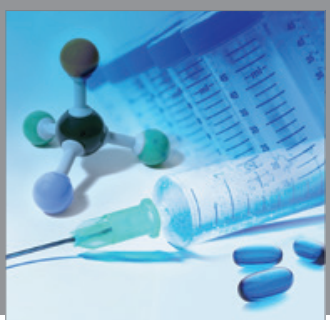

International Journal of

Medicinal Chemistry

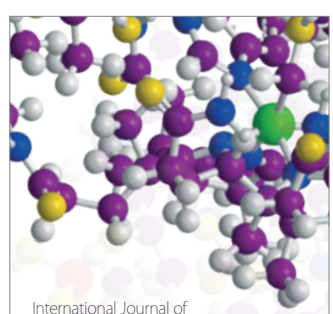

Carbohydrate Chemistry

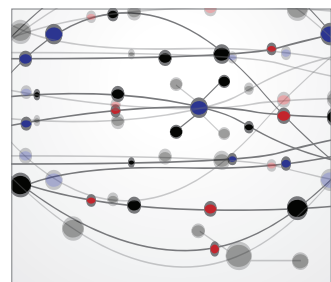

The Scientific World Journal
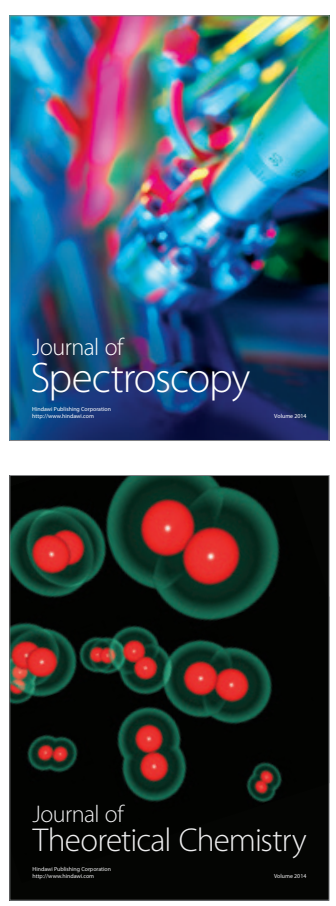
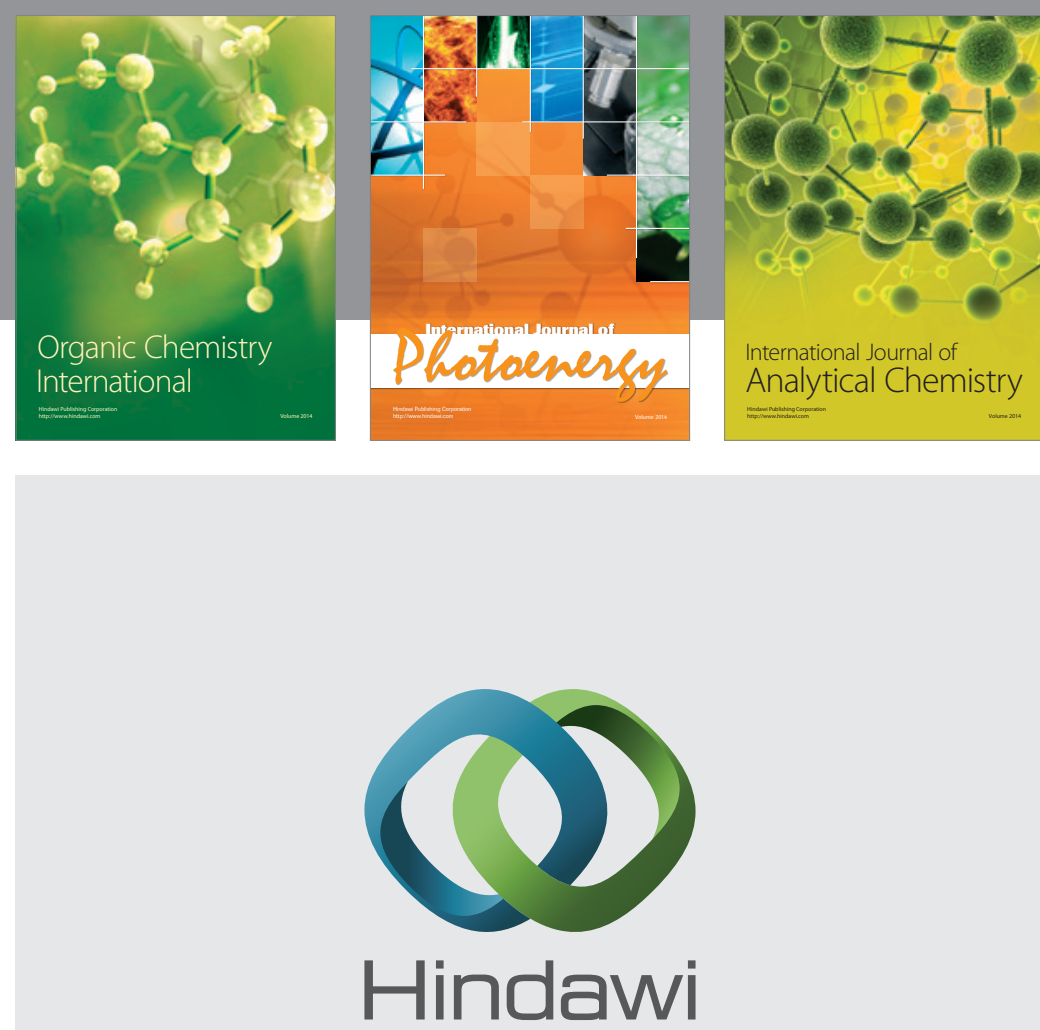

Submit your manuscripts at

http://www.hindawi.com
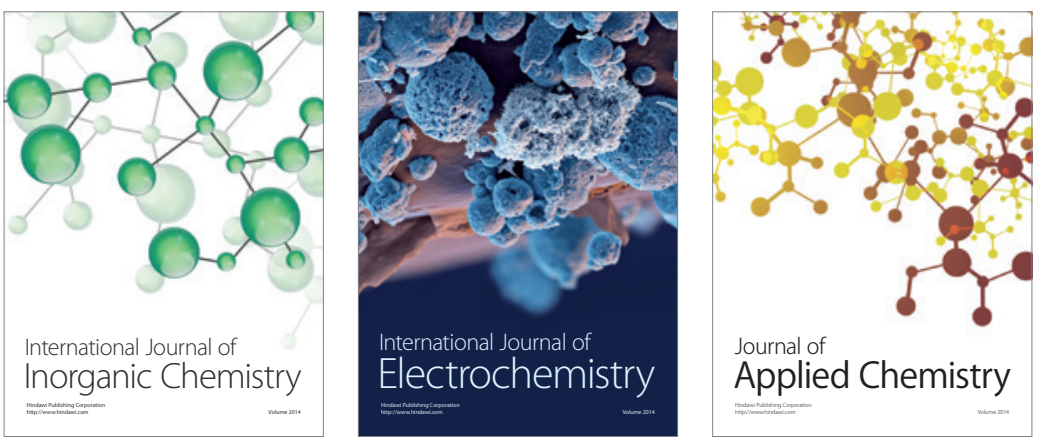

Journal of

Applied Chemistry
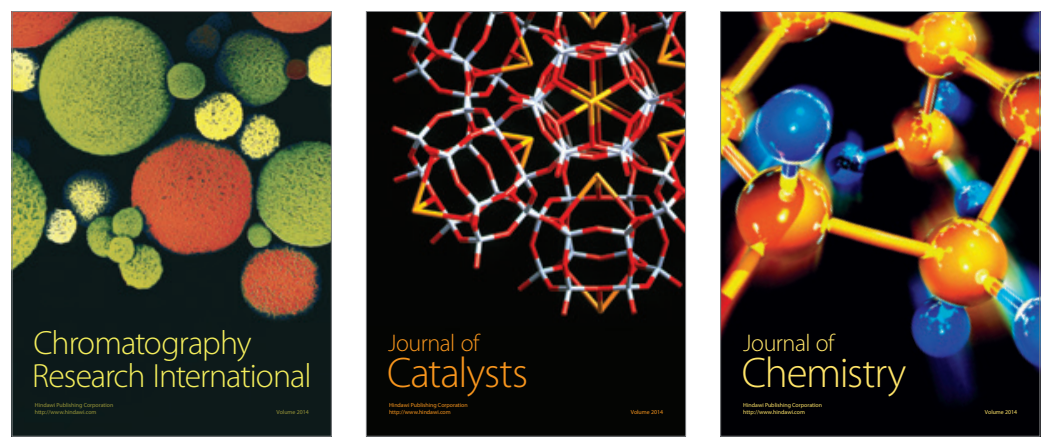
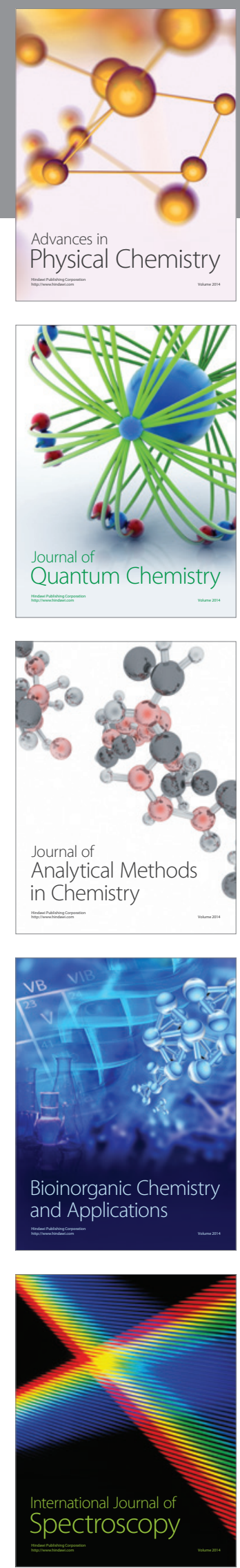